\section{Saúde Coletiva e Educação Física: um convite ao diálogo}

Public Health and Physical Education: an invitation to a dialogue

Rogério Cruz Oliveira ${ }^{1}$

${ }^{1}$ Departamento de Ciências do Movimento Humano, Universidade Federal de São Paulo. Santos SP Brasil.

O manuscrito "Saúde Coletiva e Educação Física: distanciamentos e interfaces" adota linguagem prudente, ancorada em afirmações que esclarecem a provisoriedade do texto e o risco de simplificações, dando o tom de diálogo e convidando à reflexão. Motivado por esse "convite" almejo nessa comunicação traçar apontamentos complementares que julgo relevantes.

Em relação à história da Educação Física (EF), embora as autoras afirmem que esse campo foi constituído na primeira metade do século XX, faz-se pertinente ressaltar que sua origem ocorreu no final do século XIX quando a ginástica foi introduzida nas escolas com o argumento "Mens sana in corpore sano"'2. Mencionar esse fato reforça $\mathrm{o}$ argumento trazido pelas autoras de que a EF, desde sua origem, afiliou-se ao discurso higienista e eugenista na educação dos corpos, bem como a compreensão do porquê a atividade física ainda ser pensada numa relação causal com a saúde.

Sobre esse ponto, o texto explora de forma assertiva de como a contemporaneidade tem se apropriado desse discurso em seus pronunciamentos. Entretanto, destaco um desdobramento não abordado pelas autoras: a criação de "identidades marginais", usando um termo de Fraga ${ }^{3}$. Assim, ser obeso e/ou sedentário significa, respectivamente, assumir as máximas: "[...] 'não faz exercício porque é preguiçoso'; 'é gordo porque é relaxado' $[\ldots]^{\prime 3}$. Ou seja, a causalidade atinge o plano da culpabilização individual, sem considerar outros condicionantes de saúde. Tal norteamento é fruto da aposta contemporânea no governo dos corpos: a informação ${ }^{3}$. Nesse horizonte, o investimento se dá no plano das recomendações ao invés de se investir, por exemplo, numa cultura da oferta das práticas corporais.
Tal crítica tem origem na incorporação dos referenciais teórico-metodológicos das ciências humanas no campo da EF a partir da década de 1980, bem descritas no manuscrito. Embasadas em autores clássicos da área, as autoras argumentam que a produção acadêmica à luz desse referencial permitiu o questionamento do predomínio biomédico. Porém, em nenhum momento abordam o papel da incorporação do conceito de cultura nesse campo, debatido, por exemplo, em Daolio ${ }^{4}$, merecedor ao menos de uma menção. Isso, porque é a cultura que une os conceitos de cultura corporal de movimento e práticas corporais abordado no texto.

No que se refere à formação profissional, o manuscrito não teve oportunidade de discorrer, pois foi submetido em novembro de 2015, sobre a proposta de extinção da modalidade de Bacharelado prevista por uma Minuta debatida em Audiência Pública no Conselho Nacional de Educação em dezembro de 2015. A proposta consistiu em unificar as formações de licenciatura e bacharelado em EF sob a égide de uma licenciatura ampliada. Até o momento, a discussão está suspensa e não houve nenhuma movimentação no sentido de encaminhá -la. Entretanto, registra-se que, embora a interface entre a EF e a Saúde Coletiva (SC) seja revelador de alguns distanciamentos, bem apontado pelas autoras, é na formação do bacharel que essa discussão tem se adensado. Extinguir o bacharelado seria um duro golpe nas pretensões da interface EF e SC na formação profissional.

Em síntese, trata-se de um manuscrito pertinente às duas áreas (EF e SC), mas que pela amplitude do debate pretendido permitiu a existência de lacunas, algumas das quais busquei comentar.

\section{Referências}

1. Nogueira JAD, Bosi MLM. Saúde Coletiva e Educação Física: distanciamentos e interfaces. Cien Saude Colet 2017; 22(6):1913-1922.

2. Castelani Filho L. Educação Física no Brasil: a história que não se conta. Campinas: Papirus; 1988.

3. Fraga AB. Promoção da vida ativa: nova ordem físicosanitária na educação dos corpos contemporâneos. In: Bagrichevsky M, Palma A, Estevão A, Da Ros M. A saúde em debate na educação física. Blumenau: Nova Letra; 2006. vol. 2. p. 105-118.

4. Daolio J. Educação Física e o conceito de cultura. Campinas: Autores Associados; 2005. 
